\title{
The Energy Efficiency and the Main Influencing Factors for the Logistics Industry in the Yangtze River Economic Belt in China
}

\author{
Xun Li and Chuan Lin (iD \\ Research Center for International Business and Economy, Sichuan International Studies University, Chongqing 400030, China \\ Correspondence should be addressed to Chuan Lin; sisulc@sisu.edu.cn
}

Received 18 August 2021; Revised 30 August 2021; Accepted 1 September 2021; Published 11 September 2021

Academic Editor: Daqing Gong

Copyright ( 92021 Xun Li and Chuan Lin. This is an open access article distributed under the Creative Commons Attribution License, which permits unrestricted use, distribution, and reproduction in any medium, provided the original work is properly cited.

Logistics is the booster of economic development, and it is imperative to further improve the logistics energy efficiency and adjust its development model. This paper is an attempt to investigate the logistics energy efficiency and main influencing factors of the Yangtze River Economic Belt, which is the most economically intensive region that spans East, Central, and West China. The input-oriented SBM-DEA model is employed to identify factors such as energy input, undesirable output, and service capacity output as well as the logistics energy efficiency of Yangtze River Economic Belt. Energy efficiency is then further decomposed into pure technical efficiency, scale efficiency, and technical efficiency, from the perspective of which provinces and cities are compared. The research results show that the logistics energy efficiency of Yangtze River Economic Belt needs to be further improved and that energy efficiency differs greatly among cities and provinces, indicating that the development is quite unbalanced in different areas. Therefore, the local government should develop development strategies according to the main influencing factors and constraints to the local logistics industry, so as to optimize and upgrade the energy structure of the logistics industry.

\section{Introduction}

With the prosperous economic development, the logistics industry in China has grown rapidly over recent years, and in turn, it has also played an important role in supporting China's economic development. What is more, the performance of this industry is even used to evaluate how developed a country or region is. Generally speaking, the logistics industry in China is large in scale, but it is also characterized by high cost, poor quality, and low efficiency [1]. In addition, the logistics industry consumes a lot of energy and emits a large amount of carbon dioxide. Now as China advocates energy conservation and emission reduction and pursues sustainable development, the logistics industry will also be required to further improve its energy efficiency and adjust its development model. To achieve this goal, first, research needs to be carried out on how to comprehensively investigate the efficiency of the logistics industry in China so as to assist the government in formulating proper industrial development plans and environmental protection policies.

The term "efficiency" was originally used to measure the amount of work done in a unit of time in manufacturing. Later, with the development of social economy, "efficiency" began to be widely used in economic activities. Some scholars believe that efficiency and effectiveness are mutually exclusive [2]. It means that when logistics efficiency develops in one dimension, it will inevitably lead to a regression in another dimension. Based on this, many scholars both at home and abroad have been working on how to balance economy and environment in the development of the logistics industry and how to obtain the optimal logistics output with less logistics input. Stochastic frontier analysis (SFA) and data envelopment analysis (DEA) are the two most employed methods, including the corporate logistics efficiency at the microlevel and the regional logistics efficiency at the macrolevel. SFA, as a parameterized method, is usually applicable to the single-output scenario, and it is 
necessary to determine the specific functional form of the production frontier. A wrong function form often leads to wrong results $[3,4]$. DEA, as a nonparametric technical efficiency method, does not require a specific function form was first proposed in 1978 [5]. DEA model is used to analyze the logistics efficiency of 19 warehousing companies in [6] and companies in Southeast Europe [7].

Regarding the regional logistics efficiency, DEA model is usually used as a tool to understand the development status of logistics industry in a province. The purpose of the study is to understand the development status of logistics industry in the province, find the constraints of efficiency improvement, and put forward improvement measures. MalmquistLuenberger productivity index [8] and DEA mode [9] are applied to measure the logistics efficiency for the provinces in China. Rashidi and Cullinane [10] used the DEA method to conduct empirical analysis on sample data of OECD member states. Zheng et al. [11] performed dynamic analysis of the logistics efficiency in coastal areas from 2007 to 2017 by using a method combining SBM and hierarchical regression and also taking into account carbon emission constraints. In addition, they also proposed the concepts of decrement and increment rates and further revealed the redundancy and insufficiency indicators of the system. Tian et al. [12] proposed an improved weighted preference DEA model based on slack-based measure to evaluate the sustainable efficiency of regional transportation. Through comparison of calculated and experimental results, it is found that the proposed DEA model requires fewer decision-making units than the other SBM-DEA models that do not take the weighted preference into account. Deng et al. [13] measured and evaluated the logistics performance of 30 provinces and cities in China with and without carbon emission constraints using the SBM-DEA model, analyzed the overall level and spatial characteristics of the logistics efficiency in China, and performed Regression analysis using the Tobit model to determine the driving factors. Scholars have adopted a variety of ways to improve the evaluation method of logistics efficiency. As the most commonly used DEA model in efficiency evaluation method, there are a lot of research on its improvement, and the relevant data are used to analyze the feasibility and advantages and disadvantages of the improved model. The research on the improvement of DEA is reflected in two aspects: one is to combine the traditional DEA method with other methods; the other is to improve the accuracy of DEA model by using the methods of dividing the research into stages and adding constraints in the model.

Most of the existing literatures focus on the evaluation of corporate and regional logistics efficiency [14-16]. Few conducted in-depth comparative analysis on the characteristics and differences of logistics efficiency in different regions and different periods or took into account the energy input and output efficiency, even though there are significant differences in the logistics development strategies and status quo in different regions. There are great differences in logistics development and main influencing factors in different regions, so it is necessary to carry out targeted research for specific regions, which is the main motivation of this research. To make up for the deficiencies in these literatures, this paper took into account factors such as energy input, undesirable output, and service capacity output and measured the energy efficiency of the logistics industry in the Yangtze River Economic Belt from 2010 to 2019. By decomposing the efficiency into pure technical efficiency, scale efficiency, and technical efficiency, this paper further compared and analyzed the calculated results of different cities and provinces and analyzed the factors affecting the logistics energy efficiency in detail. Based on this, targeted countermeasures and suggestions were put forward for the local governments.

The subsequent sections of this paper are organized as follows: Section 2 introduces the DEA method and constructs a nonradial SBM model for undesirable output and then elaborates on the input and output indicators and the collection and analysis of the logistics related data from 11 provinces and cities; Section 3 provides the background information of the Yangtze River Economic Belt and analyzes the logistics energy efficiency and its influencing factors, providing basis for the improvement of regional efficiency, and also conducts a comparative study of energy efficiency; and the last section puts forward some suggestions on how to maintain the sustainable development of the logistics industry and how to improve the energy efficiency of logistics.

\section{Method}

2.1. Input-Oriented CCR Model. In the basic CCR model, for area $j, \mathrm{DMU}_{j}(j=1,2, \ldots, n)$ has $m$ input indicators and $s$ output indicators. $x_{i j}$ and $y_{r j}$, respectively, represent the value of the $i$-th input indicator and the $r$-th output indicator in $\mathrm{DMU}_{j}$.

$\lambda_{j}$ represents the multiplier vector. $s_{i}^{-}$represents the excesses of input, and $s_{r}^{+}$represents the excesses of output. $\varepsilon>0$ is a non-Archimedes infinitesimal. Therefore, the input-oriented CCR model is constructed as follows:

$$
\min \left[\theta-\varepsilon\left(\sum_{i=1}^{I} s_{i}^{-}+\sum_{r=1}^{R} s_{r}^{+}\right)\right],
$$

which satisfies the following:

$$
\begin{aligned}
\sum_{j=1}^{n} x_{i j} \lambda_{j}+s_{i}^{-} & =\theta x_{i_{0}}, \\
\sum_{j=1}^{n} y_{r j} \lambda_{j}-s_{r}^{+} & =y_{r_{0}}, \\
\lambda_{j}, s_{i}^{-}, s_{r}^{+} & \geq 0,(\forall j, i, r) .
\end{aligned}
$$

2.2. Nonradial SBM Model for Undesirable Output. In fact, the traditional DEA model is usually radial based, without considering the effect of slack variables on efficiency. Tone proposed the slacks-based measure (SBM) model, which is a nonradial DEA model, with improvements in proportional 
changes of inputs and outputs and also slack variables. The nonradial SBM model for undesirable output is as follows:

$$
\min \theta_{j}=\frac{1-1 / m \sum_{i=1}^{m} s_{i_{0}}^{-} / x_{i_{0}}}{1+1 / s \sum_{r=1}^{s} s_{r_{0}}^{+} / y_{r_{0}}}
$$

which satisfies the following:

$$
\begin{aligned}
\sum_{j=1}^{n} x_{i j} \lambda_{j}+s_{i_{0}}^{-} & =x_{i_{0}}(i=1,2, \ldots, m), \\
\sum_{j=1}^{n} y_{r j} \lambda_{j}-s_{r_{0}}^{+} & =y_{r_{0}}(r=1,2, \ldots, s), \\
\sum_{j=1}^{n} \lambda_{j} & =1(j=1,2, \ldots, n), \\
\lambda_{j}, s_{i_{0}}^{-}, s_{r_{0}}^{+} & \geq 0,(\forall j, i, r) .
\end{aligned}
$$

However, for output indicators, undesired outputs can be considered, such as carbon emissions. Tone further proposed the SBM model with undesirable output, which is described as follows:

$$
\min \theta_{j}=\frac{1-1 / m \sum_{i=1}^{m} s_{i_{0}}^{-} / x_{i_{0}}}{1+1 /\left(s^{d}+s^{u}\right)\left(\sum_{r=1}^{s^{d}} s_{r_{0}}^{d+} / y_{r_{0}}^{d}+\sum_{r=1}^{s^{u}} s_{r_{0}}^{u-} / y_{r_{0}}^{u}\right)},
$$

which satisfies the following:

$$
\begin{aligned}
& \sum_{j=1}^{n} x_{i j} \lambda_{j}+s_{i_{0}}^{-}=x_{i_{0}}(i=1,2, \ldots, m), \\
& \sum_{j=1}^{n} y_{r j}^{d} \lambda_{j}-s_{r_{0}}^{d+}=y_{r_{0}}^{d}\left(r=1,2, \ldots, s^{d}\right), \\
& \sum_{j=1}^{n} y_{r j}^{u} \lambda_{j}+s_{r_{0}}^{u-}=y_{r_{0}}^{u}\left(r=1,2, \ldots, s^{u}\right), \\
& \sum_{j=1}^{n} \lambda_{j}=1(j=1,2, \ldots, n), \\
& \lambda_{j}, s_{i_{0}}^{-}, s_{r_{0}}^{d+}, s_{r_{0}}^{u-} \geq 0,(\forall j, i, r),
\end{aligned}
$$

where $s_{i_{0}}^{-}, s_{r_{0}}^{d+}$ and $s_{r_{0}}^{u-}$ denote the slack variables of the inputs and the desirable and undesirable outputs, respectively, and $s^{d}$ and $s^{u}$ are the number of desirable and undesirable outputs, respectively. In addition, the model is nonlinear. Therefore, it can be converted into a linear formula through Charnes-Cooper transformation [16]:

Let

$$
\begin{gathered}
\Lambda_{j}=t \lambda_{j}, s_{i_{0}}^{-}=t s_{i_{0}}^{-}, \\
s_{r_{0}}^{d+}=t s_{r_{0}}^{d+}, s_{r_{0}}^{u-}=t s_{r_{0}}^{u-}, \\
\min \theta_{j}=t-\frac{1}{m} \sum_{i=1}^{m} \frac{s_{i_{0}}^{-}}{x_{i_{0}}},
\end{gathered}
$$

which is subject to the following:

$$
\begin{aligned}
& t+\frac{1}{s^{d}+s^{u}}\left(\sum_{r=1}^{s^{d}} \frac{s_{r_{0}}^{d+}}{y_{r_{0}}^{d}}+\sum_{r=1}^{s^{u}} \frac{s_{r_{0}}^{u-}}{y_{r_{0}}^{u}}\right)=1, \\
& \sum_{j=1}^{n} x_{i j} \Lambda_{j}+s_{i_{0}}^{-}=t x_{i_{0}}(i=1,2, \ldots, m), \\
& \sum_{j=1}^{n} y_{r j}^{d} \Lambda_{j}-s_{r_{0}}^{d+}=\operatorname{ty}_{r_{0}}^{d}\left(r=1,2, \ldots, s^{d}\right), \\
& \sum_{j=1}^{n} y_{r j}^{u} \Lambda_{j}+s_{r_{0}}^{u-}=\operatorname{ty}_{r_{0}}^{u}\left(r=1,2, \ldots, s^{u}\right), \\
& \sum_{j=1}^{n} \Lambda_{j}=t(j=1,2, \ldots, n), \\
& \Lambda_{j}, s_{i_{0}}^{-}, s_{r_{0}}^{d+}, s_{r_{0}}^{u-} \geq 0, t>0(\forall j, i, r) .
\end{aligned}
$$

Therefore, when $\theta^{*}=1$, the regional logistics efficiency $\left(\mathrm{DMU}_{0}\right)$ is the SBM efficiency, which means that all the slacks of the inputs and the desirable and undesirable outputs are zero. In addition, for areas where SBM is ineffective, there is the following expression: $\bar{x}_{0} \leftarrow x_{0}-s^{-*}$, $\hat{y}_{0}^{d} \leftarrow y_{0}^{d}+s^{d+*}, \quad y_{0}^{u} \leftarrow y_{0}^{u}-s^{u-*}$, which is called SBM projection.

\section{Data Collection}

The Yangtze River Economic Belt in China consists of 11 provinces and cities. It has a total area of approximately $2,052,300 \mathrm{~km}^{2}$, which accounts for about one fifth of the territorial area of China, but as an economically intensive region, it contributes over $40 \%$ of the GDP in China. With waters, roads, ports, and shores in the Yangtze River Economic Belt, the basin economy is rapidly developing and driving the economic development of the whole country. Figure 1 shows the geographic locations of the 11 provinces and cities, in which Chongqing, Sichuan, Yunnan, and Guizhou are in the upper reaches (in red), Anhui, Jiangxi, Hubei, and Hunan are in the middle reaches (in blue), and Shanghai, Jiangsu, and Zhejiang are in the lower reaches (in green).

In the existing data statistics, the logistics statistics system is not yet mature. Considering that the added value of transportation, warehousing, and postal services account for $85 \%$ of the total added value of the logistics industry, this research reviewed literatures and finally decided to use the related data from the EPS database and the statistical yearbooks as the logistics data for analysis. The specific indicators and their values are as follows.

\subsection{Input Indicators}

3.1.1. Capital Input. The capital stock of logistics fixed assets during 2010-2019. The capital stock of fixed assets needs to be estimated based on the historical fixed asset investment 


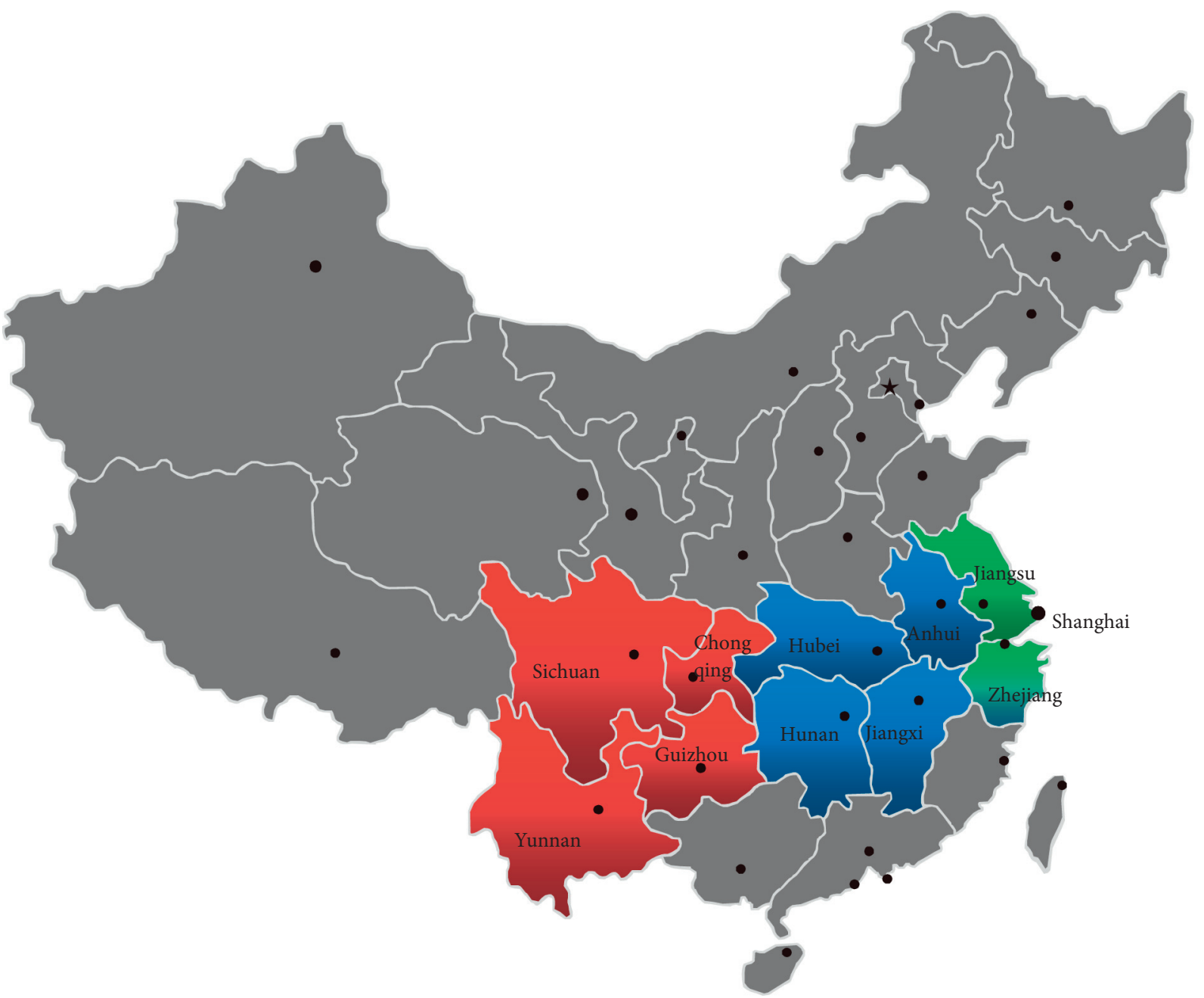

Figure 1: Geographical locations of the provinces and cities in the Yangtze River Economic Belt.

data using the perpetual inventory method. The calculation formula is as follows:

$$
K_{\mathrm{it}}=K_{\mathrm{it}-1}\left(1-\delta_{\mathrm{it}}\right)+I_{\mathrm{it}},
$$

where $K_{\mathrm{it}}$ is the capital stock in a year; $\delta_{\mathrm{it}}$ is the depreciation rate in a year; and $I_{\mathrm{it}}$ is the fixed asset investment in a year. The investment $I_{\mathrm{it}}$ in the logistics industry in a year is extracted from the investments in the fixed assets of transportation, postal services, and telecommunications from 2010 to 2019. The capital stock $K_{0}$ in the base year is the fixed asset investment in the logistics industry in each region in 1996 divided by $10 \%$. By reference to relevant literatures, the depreciation rate $\delta_{\text {it }}$ of fixed assets in the logistics industry is set at $12.1 \%$. After the data of fixed asset investment in transportation, warehousing and postal services in the 11 provinces were collected and sorted out from the EPS database. These data were deflated using the fixed asset investment price index for transportation, warehousing, and postal services to eliminate the impacts of price changes.

3.1.2. Labor Input. As the data indices of labor time, type, and quality are not available, the number of employees is considered. We collect the related data from 2010 to 2019 in the China Statistical Yearbook, which is used as the number of employees in the logistics industry.

3.1.3. Infrastructure Input. Road infrastructure is a prerequisite for the smooth operation of logistics. The total length of transportation routes is indicative of the scale of a regional logistics road network. In this paper, the sum of the service mileage of railways and roads and that of inland river navigation in each province or city from the statistical yearbook is used as the infrastructure input in the local logistics industry in the year.

3.1.4. Energy Input. The data of various energy consumptions by transportation, warehousing, and postal services in the provinces and cities of the Yangtze River Economic Belt from 2010 to 2018 were collected from the EPS database and the China Energy Statistical Yearbook. However, the figures in 2019 are missing, so the energy data were predicted by the simple moving average method and converted into standard coal equivalents using the standard coal conversion coefficients for the various types of energy shown in the Table 1 . 
TABle 1: Standard coal conversion coefficients for main energy sources.

\begin{tabular}{lc}
\hline Energy & Standard coal conversion coefficient \\
\hline Coal & $0.9714 \mathrm{kgCE} / \mathrm{kg}$ \\
Gasoline & $1.4714 \mathrm{kgCE} / \mathrm{kg}$ \\
Kerosene & $1.4714 \mathrm{kgCE} / \mathrm{kg}$ \\
Diesel & $1.4571 \mathrm{kgCE} / \mathrm{kg}$ \\
Fuel oil & $1.4286 \mathrm{kgCE} / \mathrm{kg}$ \\
LPG & $1.7132 \mathrm{kgCE} / \mathrm{m}^{3}$ \\
Natural gas & $1.3300 \mathrm{kgCE} / \mathrm{m}^{3}$ \\
Thermal energy & $0.03412 \mathrm{kgCE} / \mathrm{MJ}$ \\
Power & $0.404 \mathrm{kgCE} / \mathrm{kWh}$
\end{tabular}

Data source: General Principles for Calculation of Comprehensive Energy Consumption (GB/T 2589-2008).

\subsection{Output Indicators}

3.2.1. Logistics GDP Output. In this paper, the GDP of transportation, warehousing, and postal services in each province or city from the EPS database and the China Statistical Yearbook is used as the GDP of the logistics industry.

3.2.2. Service Capacity Output. In this paper, the comprehensive turnover is used to measure the service capacity output. The calculation formula is as follows: comprehensive turnover $=$ cargo turnover + (passenger turnover $\times$ passenger-cargo conversion coefficient).

Cargo turnover and passenger turnover data in different areas and years can be obtained directly from the statistical yearbook. The generally used passenger-cargo conversion coefficients in China are shown in Table 2

3.2.3. Carbon Emission Output. Carbon emission is an undesirable output. In this paper, the consumption of each energy source by transportation, warehousing, and postal services in each province in 2010-2019 collected from the EPS database and the China Energy Statistics Yearbook was first multiplied by the corresponding energy carbon emission coefficient, and then, the products were totaled up as the carbon emission value of each of the 11 provinces and cities. After that, the carbon emission values were normalized.

\section{Result and Discussion}

This paper conducted empirical analysis using the software MAX DEA and calculated the logistics energy efficiency of the 11 provinces and cities in the Yangtze River Economic Belt from two perspectives-economic development and environment. The economic development involves technical efficiency and scale efficiency, while the environment involves energy efficiency and carbon emission efficiency. The data analysis period is from 2010 to 2019 , and there are 110 DMUs. The calculated logistics energy efficiency values of the 11 provinces and cities are shown in Table 3.

Overall, the logistics energy efficiency of the 11 provinces and cities in the Yangtze River Economic Belt was not quite satisfactory. The provinces and cities whose comprehensive
TABle 2: Passenger-cargo conversion coefficients.

\begin{tabular}{lc}
\hline Shipping method & Passenger-cargo conversion coefficient \\
\hline Railway & 1 \\
Road & 0.1 \\
Waterway & 1 \\
\hline
\end{tabular}

Data source: calculated according to the Chinese statistical system.

logistics energy efficiency was 1 accounted for a relatively small proportion, and the logistics energy efficiency of different provinces and cities varied greatly, with the minimum value being 0.08 . What is more, for each province or city, the comprehensive logistics energy efficiency fluctuated greatly. Shanghai was relatively stable, indicating that its logistical resources were relatively effectively allocated and that there was little excess input. Moreover, compared with those in the previous literatures that did not consider service capacity output and energy input and output, the calculated comprehensive logistics energy efficiency in this paper dropped significantly, which shows that the energy input for the development of the logistics industry in the Yangtze River Economic Belt is not optimized enough, and that compared to the input, the service capacity output is also seriously insufficient. This paper further calculated the sum of the logistics energy efficiency values of the 11 provinces and cities from 2010 to 2019, with the detailed results and comparisons shown in Figure 2.

An interesting phenomenon can be seen from Figure 2: the energy efficiency of the logistics industry from 2010 to 2019 showed a "smiling-face" curve. Through analysis, the possible reasons are as follows: the overall scale of the logistics industry was not large in 2010 , and thus, the requirements were not high for operations and management, and various resources were rationally allocated. During 2010-2017, the logistics industry saw a large growth, and in this process, the resource structure became seriously unbalanced, leading to resources redundancy and waste and extremely low energy input-output efficiency. However, in recent years, with the development of the modern logistics industry, the resources allocation has been continuously optimized, and with the awareness of carbon emission reduction enhanced and relevant technologies applied, the overall energy efficiency of the logistics industry has been continuously improved. The research further analyzed the average energy efficiency of logistics in the upper, middle, and lower reaches from 2010 to 2019 and found that the logistics energy efficiency in provinces and cities in the lower reaches was much higher than that in provinces and cities in the middle and upper reaches (see Figure 3), which is in line with the conclusions of most literatures.

Then, the research analyzed the pure technical efficiency (PTE) and scale efficiency (SE) of the logistics industry in 11 provinces and cities in the Yangtze River Economic Belt from 2010 to 2019. The PTE value indicates how effective the utilization of various production factors is by the logistics industry without the effect of scale. The scale efficiency reflects how far the scale of the logistics industry in a province is from the optimal scale. The data analysis results can be seen in Table 4 and Figure 4. 
TaвLE 3: Logistics energy efficiency of the provinces and cities in the Yangtze River Economic Belt.

\begin{tabular}{lccccccccccc}
\hline Year & Chongqing & Sichuan & Yunnan & Guizhou & Anhui & Jiangxi & Hubei & Hunan & Shanghai & Jiangsu & Zhejiang \\
\hline 2010 & 0.15 & 0.10 & 1.00 & 1.00 & 1.00 & 1.00 & 0.58 & 0.35 & 1.00 & 0.72 & 1.00 \\
2011 & 0.16 & 0.10 & 0.61 & 0.83 & 0.59 & 0.91 & 0.33 & 0.32 & 1.00 & 0.41 & 0.39 \\
2012 & 0.15 & 0.11 & 0.59 & 0.72 & 0.46 & 0.60 & 0.33 & 0.30 & 1.00 & 0.41 & 0.39 \\
2013 & 0.13 & 0.10 & 0.13 & 0.33 & 0.22 & 0.21 & 0.19 & 0.13 & 0.58 & 0.31 & 0.17 \\
2014 & 0.14 & 0.11 & 0.14 & 0.32 & 0.23 & 0.18 & 0.21 & 0.16 & 1.00 & 0.35 & 0.22 \\
2015 & 0.15 & 0.12 & 0.17 & 0.31 & 0.17 & 0.21 & 0.23 & 0.16 & 0.62 & 0.37 & 0.26 \\
2016 & 0.21 & 0.18 & 0.23 & 0.38 & 0.21 & 0.17 & 0.26 & 0.21 & 0.60 & 0.31 \\
2017 & 0.08 & 0.12 & 0.19 & 0.38 & 0.94 & 0.25 & 0.23 & 0.17 & 0.77 & 0.42 & 0.37 \\
2018 & 0.44 & 0.40 & 0.56 & 1.00 & 1.00 & 1.00 & 0.52 & 0.68 & 0.91 & 0.43 & 0.28 \\
2019 & 0.50 & 0.44 & 0.61 & 1.00 & 1.00 & 0.72 & 0.48 & 0.60 & 1.00 & 1.00 & 1.00 \\
\hline
\end{tabular}

Data source: calculated according to the Chinese statistical system.

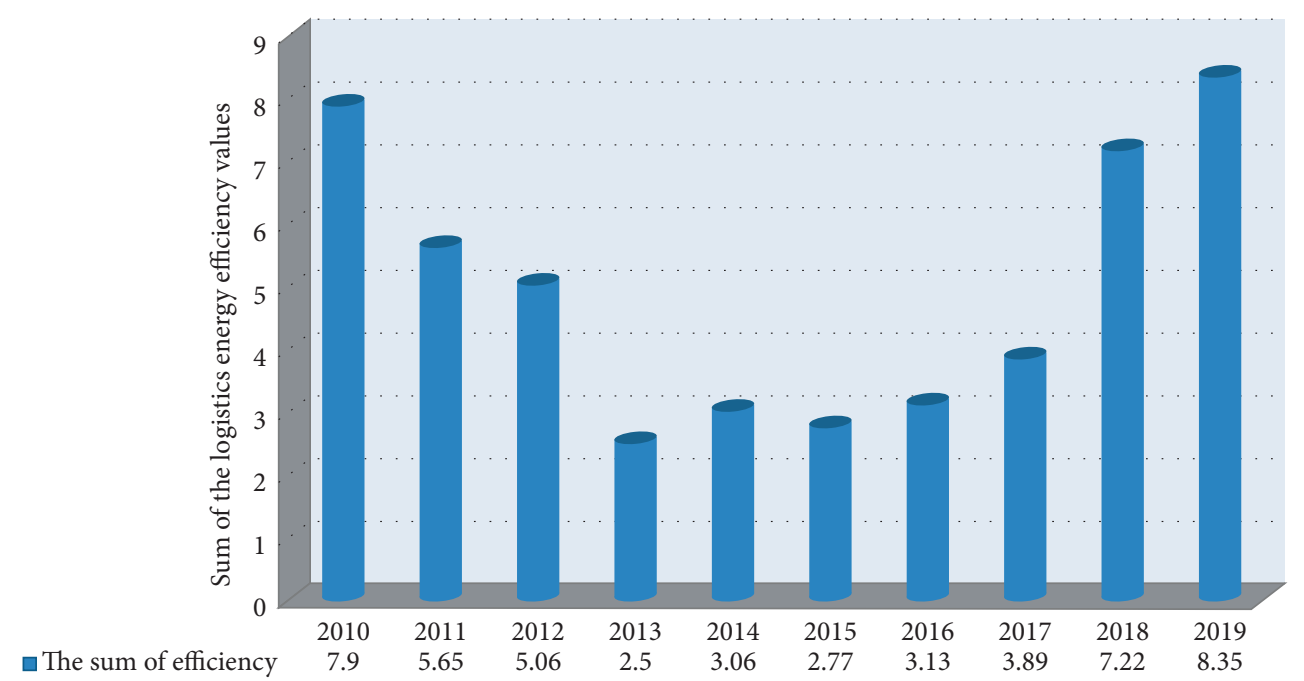

Figure 2: Sum of the logistics energy efficiency values of the 11 provinces and cities from 2010 to 2019.

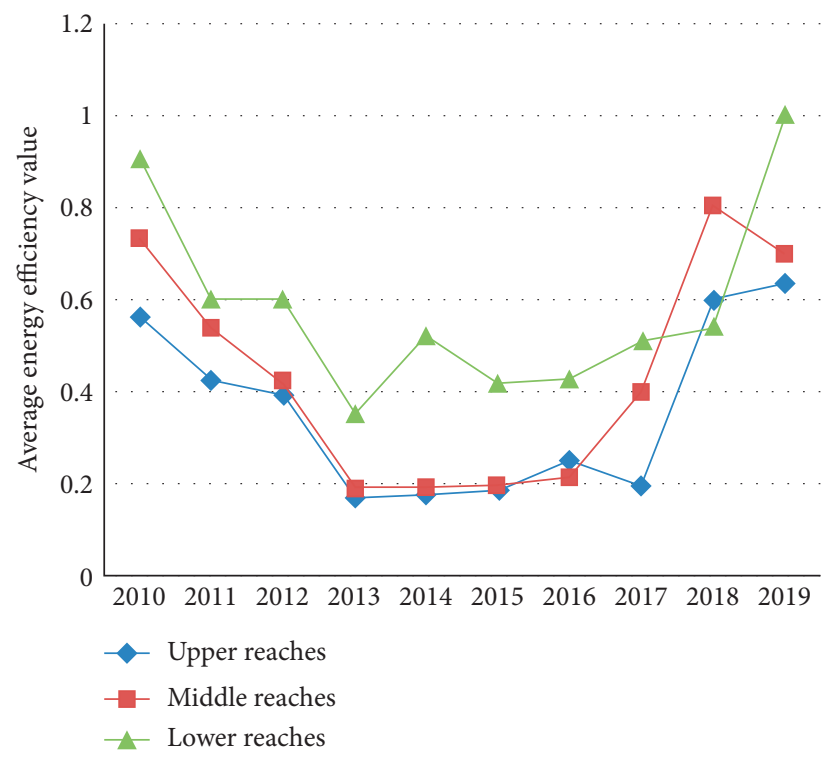

Figure 3: Average energy efficiency values of the logistics industry in the upper, middle, and lower reaches of the Yangtze River Economic Belt from 2020 to 2019. 
TABle 4: PTE and SE of the logistics industry in 11 provinces and cities in the Yangtze River Economic Belt from 2010 to 2019.

\begin{tabular}{ccccccccccccc}
\hline Year & & Chongqing & Sichuan & Yunnan & Guizhou & Anhui & Jiangxi & Hubei & Hunan & Shanghai & Jiangsu & Zhejiang \\
\multirow{2}{*}{2010} & PTE & 0.63 & 0.24 & 1.00 & 1.00 & 1.00 & 1.00 & 0.68 & 0.49 & 1.00 & 0.82 & 1.00 \\
& SE & 0.24 & 0.40 & 1.00 & 1.00 & 1.00 & 1.00 & 0.86 & 0.72 & 1.00 & 0.87 & 1.00 \\
\hline \multirow{2}{*}{2011} & PTE & 0.59 & 0.23 & 0.63 & 0.91 & 1.00 & 1.00 & 0.53 & 0.45 & 1.00 & 0.55 & 0.51 \\
& SE & 0.27 & 0.44 & 0.97 & 0.92 & 0.59 & 0.91 & 0.61 & 0.70 & 1.00 & 0.74 & 0.77 \\
\hline \multirow{2}{*}{2012} & PTE & 0.54 & 0.22 & 0.60 & 0.84 & 0.64 & 0.89 & 0.49 & 0.43 & 1.00 & 0.55 & 0.48 \\
& SE & 0.28 & 0.48 & 0.99 & 0.86 & 0.72 & 0.67 & 0.67 & 0.71 & 1.00 & 0.74 & 0.81 \\
\hline \multirow{2}{*}{2013} & PTE & 0.49 & 0.22 & 0.33 & 0.62 & 0.33 & 0.60 & 0.35 & 0.29 & 1.00 & 0.44 & 0.28 \\
& SE & 0.27 & 0.45 & 0.40 & 0.54 & 0.67 & 0.34 & 0.52 & 0.45 & 0.58 & 0.71 & 0.63 \\
\hline \multirow{2}{*}{2014} & PTE & 0.45 & 0.21 & 0.29 & 0.58 & 0.31 & 0.46 & 0.34 & 0.28 & 1.00 & 0.45 & 0.30 \\
& SE & 0.31 & 0.52 & 0.48 & 0.55 & 0.73 & 0.40 & 0.61 & 0.56 & 1.00 & 0.78 & 0.72 \\
\hline \multirow{2}{*}{2015} & PTE & 0.40 & 0.22 & 0.30 & 0.53 & 0.25 & 0.43 & 0.35 & 0.26 & 0.67 & 0.49 & 0.33 \\
& SE & 0.38 & 0.55 & 0.58 & 0.59 & 0.68 & 0.48 & 0.66 & 0.61 & 0.93 & 0.76 & 0.80 \\
\hline \multirow{2}{*}{2016} & PTE & 0.41 & 0.27 & 0.33 & 0.56 & 0.24 & 0.40 & 0.36 & 0.29 & 0.62 & 0.44 & 0.42 \\
& SE & 0.51 & 0.64 & 0.69 & 0.68 & 0.87 & 0.42 & 0.72 & 0.72 & 0.96 & 0.71 & 0.88 \\
\hline \multirow{2}{*}{2017} & PTE & 0.36 & 0.21 & 0.29 & 0.55 & 1.00 & 0.45 & 0.33 & 0.25 & 0.79 & 0.52 & 0.39 \\
& SE & 0.23 & 0.58 & 0.66 & 0.69 & 0.94 & 0.55 & 0.70 & 0.69 & 0.98 & 0.81 & 0.87 \\
\hline \multirow{2}{*}{2018} & PTE & 0.57 & 0.43 & 0.56 & 1.00 & 1.00 & 1.00 & 0.57 & 0.70 & 0.91 & 0.53 & 0.33 \\
& SE & 0.78 & 0.94 & 1.00 & 1.00 & 1.00 & 1.00 & 0.90 & 0.96 & 0.99 & 0.81 & 0.85 \\
\hline \multirow{2}{*}{2019} & PTE & 0.59 & 0.46 & 1.00 & 1.00 & 1.00 & 0.79 & 0.53 & 0.64 & 1.00 & 1.00 & 1.00 \\
& SE & 0.84 & 0.95 & 0.61 & 1.00 & 1.00 & 0.91 & 0.90 & 0.94 & 1.00 & 1.00 & 1.00 \\
\hline
\end{tabular}

Data source: calculated according to the Chinese statistical system.

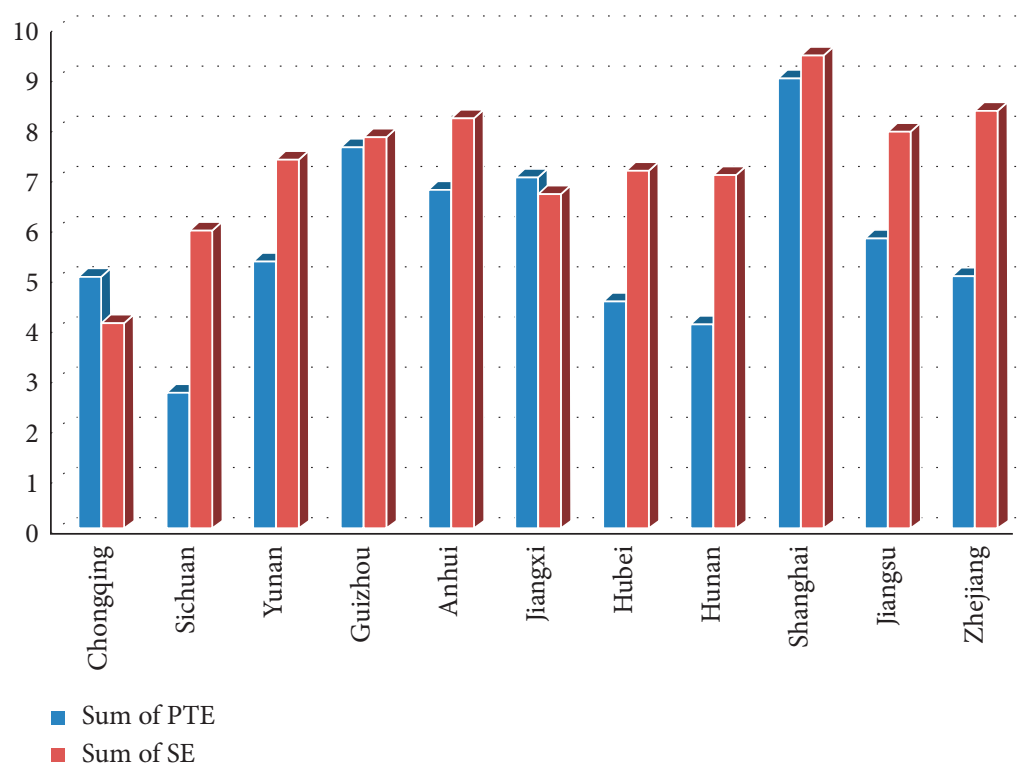

FIgURe 4: PTE and SE of the logistics industry in the provinces and cities in the Yangtze River Economic Belt from 2010 to 2019.

Based on the information in the chart, Shanghai has both high technical efficiency and scale efficiency, followed by Guizhou. Hubei and Hunan have low PTE but high SE, indicating that, in these provinces and cities, the resources are redundant but were not well utilized and that the technology level is the key factor that restricts the highquality development of the logistics industry in these areas. Jiangxi's PTE has reached a high level, but there is still room for improvement in SE. In the future, Jiangxi should work on the production and operation scale. Sichuan is at a relatively low level in both PTE and SE. In the subsequent development, not only should it focus on improving the technical level, but it also needs to enhance its management and pay attention to the adjustment of the industrial scale.

\section{Conclusions}

This paper took into account factors such as energy input, undesirable output, and service capacity output and measured the energy efficiency of the logistics industry in the Yangtze River Economic Belt. The measurement results show that the logistics energy efficiency is relatively low and 
varies greatly between different provinces and cities. The middle and upper reaches' logistics energy efficiency is much lower than that in lower reaches. Since the provinces in the middle reaches are the bridge connecting upstream and downstream provinces and cities, the daily logistics quantity is very large, but their technical and management level need to be further improved.

This paper also compared and analyzed the calculation results of PTE, SE, and TE in different provinces and cities and found that the energy efficiency of the logistics industry in different provinces and cities is affected and constrained by different factors. When formulating logistics development strategies, local government should fully consider the main factors affecting the local logistics industry. This paper proves the feasibility of SBM-DEA model in the study of logistics energy efficiency and influencing factors, so the model can also be applied to the study of logistics efficiency in other provinces and cities. At the same time, according to the PTE and Se obtained by the model, the local government can adjust measures to local conditions, provinces, and cities with low PTE and high SE and should not go too far with the economies of scale but focus on introducing advanced logistics technologies, improving energy utilization and planning rational resources allocation. Those with relatively high PTE but low SE should increase the scale of operation so as to benefit from the economies of scale. Those with low PTE and SE should first improve both management and technology levels, including upgrading the logistics technologies, introducing advanced technologies and equipment, and making scientific resource input planning, and then pay attention to adjusting the industrial scale and optimizing the allocation of resources to achieve the economies of scale.

\section{Data Availability}

The data used to support the findings of this study are available from the corresponding author upon request.

\section{Conflicts of Interest}

The authors declare that they have no conflicts of interest.

\section{Acknowledgments}

The authors acknowledge funding from the Chongqing Social Science Fund Project (no. 2020YBJJ161), Humanities and Social Sciences Research Project of Chongqing $\mathrm{Mu}-$ nicipal Education Commission (no. 21SKGH129), and Sichuan International Studies University School-level Scientific Research Project (no. sisu202007).

\section{References}

[1] X. C. Rong, Improve Quality and Efficiency to Develop Modern Logistics, Economic Daily, Beijing, China, 2017.

[2] G. J. Bamber and R. D. Lansbury, "Management strategy and new technology in retail distribution: a comparative case study," Journal of Management Studies, vol. 25, no. 3, pp. 197-216, 1988.
[3] K. M. Kortelainen, "Stochastic non-smooth envelopment of data: semi-parametric frontier estimation subject to shape constraints," Journal of Productivity Analysis, vol. 38, no. 1, pp. 11-28, 2012.

[4] L. Chen and G. Jia, "Environmental efficiency analysis of China's regional industry: a data envelopment analysis (DEA) based approach," Journal of Cleaner Production, vol. 142, no. 2, pp. 846-853, 2017.

[5] A. Charnes, W. W. Cooper, and E. Rhodes, "Measuring the efficiency of decision making units," European Journal of Operational Research, vol. 2, no. 6, pp. 429-444, 1978.

[6] A. Hamdan and K. J. Rogers, "Evaluating the efficiency of 3PL logistics operations," International Journal of Production Economics, vol. 113, no. 1, pp. 235-244, 2008.

[7] P. Ketikidis, S. Koh, N. Dimitriadis, A. Gunasekaran, and M. Kehajova, "The use of information systems for logistics and supply chain management in South East Europe: current status and future direction," Omega, vol. 36, no. 4, pp. 592-599, 2008.

[8] W. W. Wang and Y. Y. Ma, "The efficiency of regional logistics industry in China based on the three-stage DEA model using malmquist-luenberger index," Systems Engineering, vol. 3, pp. 66-75, 2012.

[9] J. Zhang and J. Zhang, "A comprehensive research on logistics efficiency in China based on three-stage DEA model," Management World, vol. 8, pp. 178-179, 2016.

[10] K. Rashidi and K. Cullinane, "Evaluating the sustainability of national logistics performance using data envelopment analysis," Transport Policy, vol. 74, pp. 35-46, 2019.

[11] W. Zheng, X. Xu, and H. Wang, "Regional logistics efficiency and performance in China along the belt and road initiative: the analysis of integrated DEA and hierarchical regression with carbon constraint," Journal of Cleaner Production, vol. 276, Article ID 123649, 2020.

[12] N. Tian, S. Tang, A. Che, and P. Wu, "Measuring regional transport sustainability using super-efficiency sbm-dea with weighting preference," Journal of Cleaner Production, vol. 242, Article ID 118474, 2019.

[13] F. Deng, L. Xu, Y. Fang, Q. Gong, and Z. Li, "PCA-DEATOBIT regression assessment with carbon emission constraints of China's logistics industry," Journal of Cleaner Production, vol. 271, Article ID 122548, 2020.

[14] R. C. Dyson and E. A. Shale, "Data envelopment analysis, operational research and uncertainty," Journal of the Operational Research Society, vol. 61, no. 5-6, pp. 25-34, 2010.

[15] Q. Huang, "Measurement of logistics efficiency in countries along the silk road economic belt based on the PCA-DEA method," Knowledge Economy, vol. 490, no. 4, pp. 20-21, 2019.

[16] P. Bajec and D. Tuljak-Suban, "An integrated analytic hierarchy process-slack based measure-data envelopment analysis model for evaluating the efficiency of logistics service providers considering undesirable performance criteria," Sustainability, vol. 11, no. 8, p. 18, 2019. 